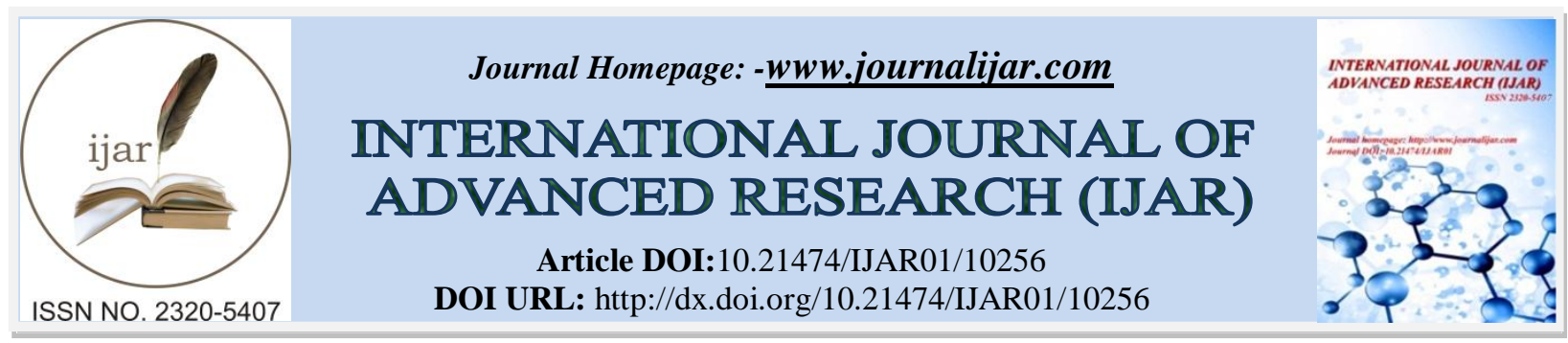

RESEARCH ARTICLE

\title{
GAMMA KNIFE RADIOSURGERY IN PITUITARY TUMORS
}

\author{
Jitendra Bhadoria, Maneet Gill, Chinmaya Srivastava, Darpan Gupta, Lokesh Gautam and Sudhanshu \\ Aggrawal
}

\section{Manuscript Info}

Manuscript History

Received: 14 October 2019

Final Accepted: 16 November 2019

Published: December 2019

\section{Introduction:-}

Pituitary adenomas are very common lesions, constituting between 10 and $20 \%$ of all primary brain tumors(1,2). Epidemiological studies have demonstrated that nearly $20 \%$ of the general population has a pituitary adenoma(2). Pituitary adenomas are broadly classified into two groups. The first category consists of tumors that secrete excess amounts of normal pituitary hormones, The second category of pituitary adenomas is composed of tumors that do not secrete any known biologically active pituitary hormones For both types of pituitary adenomas, a recurrence resulting from tumor invasion into surrounding structures or in complete tumor resection is quite common. Longterm tumor control rates after microsurgery alone vary from 50 to $80 \%$ (3-5). Radiation therapy or radiosurgery can be administered postoperatively as adjuvant therapy to inhibit recurrent growth or later when clinical symptoms or neuroimaging findings indicate a recurrence. These therapies may also be used postoperatively to treat known residual tumor following incomplete resection.

Conventional fractionated radiotherapy was initially designed to treat all kinds of cancers and subsequently, pituitary tumours were among the first brain tumours to be treated [6-8]. However, the dose that can be given is limitied to 45-50 Gy with approximately $1.8 \mathrm{~Gy}$ given per day. This leads to a very slow reduction of elevated pituitary hormones. The broad field of radiation causes a high incidence of pituitary insufficiency [9,10]. Furthermore, major complications, although rare, involve damage to the optic pathways [11], necrosis in other brain areas and even neuropsychological complications [12]. In addition, the relative risk of the development of second brain tumour after fractionated radiotherapy is estimated to be significantly increased compared to the general population [13,14]. The limitations of radiotherapy have stimulated the interest to develop alternative methods to deliver radiation to pituitary tumours. Stereotactic radiosurgery allows the delivery of radiation with a high degree of precision to the target, and low doses to the surrounding tissues.

\section{Gamma knife radiosurgery:-}

In 1968 Lars Leksell carried out the first gamma thalamotomy in a patient with untractable cancer pain using the first stereotactic radiosurgical unit in Stockholm For the radiosurgical interventions the Leksell Stereotactic System is used. The procedure has recently been reviewed in detail. A special helmet allows irradiation with 201 gamma beams of $60 \mathrm{Co}$, and the irradiation is given as a single treatment lasting about 30 minutes. The treatment is carried out in an outpatient setting in local anesthesia and a stereotactic frame is attached to the skull. Before treatment, a stereotactic magnetic resonance imaging (MRI) with pre- and post-gadolineum axial and coronal views and three dimensional volume axial sequences is performed. Coronal images are also obtained by reformatting the axial scan information which reduces distortion. Dose planning requires delineation of the targets and the adjacent structures, 
especially the optic chiasm. The gamma knife has four collimator sizes, 4, 8, 14 and $18 \mathrm{~mm}$, through which ionizing radiation is delivered. In general the smaller the size of collimator used, the steeper the fall in radiation involving tissue outside the target. The dose plan frequently involves the use of multiple shots so as to deliver to the periphery of the tumour approximately $50 \%$ of the maximum dose of radiation administered (50\% isodose line).

We present our series of 152 cases of pituitary tumors, treated with gamma knife radiosurgery over the last 10 years. This investigation was conducted to evaluate the effects of gamma knife radiosurgery on the growth and safety in the treatment of pituitary adenomas.

\section{Material And Method:-}

This retrospective study carried out at the apex tertiary care centre of the armed forces medical setup in India, retrospectively analysed the use of Gamma knife radiosurgery as a primary or adjunctive form of therapy for pituitary tumors offered to patients over a period of 10 years at this centre. The radiosurgery was carried out using a Leksell Gamma knife Elekta instruments, Stockholm, Sweden, model 4 C, installed in 2007. The gamma knife was planned with safety tolerance limit of dose to brain stem, cranial nerve not to exceed 12 Gy. The prescribed tumor margin dose was more than $13 \mathrm{~Gy}$ if possible. A retrospective chart analysis of 152 patients who underwent a radio surgical procedure as a primary or adjunctive therapy was carried out.

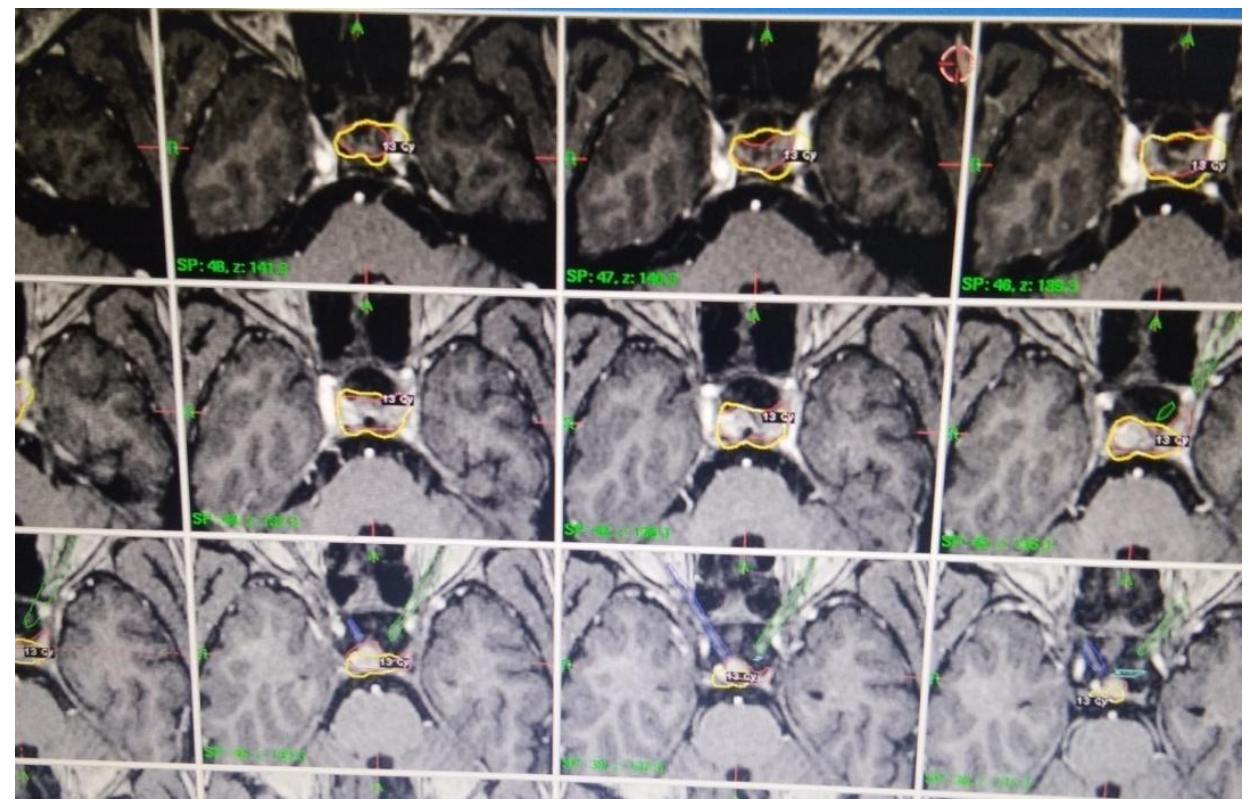

Fig1:- 32 years old female underwent gamma knife radiosurgery for residual pituitary adenoma. Dose of 13 Gy was given.

\begin{tabular}{|l|l|}
\hline Age range & No \\
\hline $20-30$ & 17 \\
\hline $31-40$ & 51 \\
\hline $41-50$ & 27 \\
\hline $51-60$ & 33 \\
\hline $61-70$ & 17 \\
\hline $71-80$ & 06 \\
\hline $81-90$ & 01 \\
\hline
\end{tabular}

\begin{tabular}{|l|l|l|l|l|l|}
\hline Mean age & Median age & Gender & Mean dose & Median dose & Mean volume \\
\hline 45.78 & 43.9 & Male $: 86$ & $17.08 \mathrm{~Gy}$ & $16 \mathrm{~Gy}$ & $4.028 \mathrm{cc}$ \\
\hline & & Female $: 66$ & & & \\
\hline
\end{tabular}

\begin{tabular}{|l|l|l|}
\hline Parameter & Mean & Median \\
\hline Margin dose & $15.53 \mathrm{~Gy}$ & $15.5 \mathrm{~Gy}$ \\
\hline
\end{tabular}




\begin{tabular}{|l|l|l|}
\hline Max dose & $30.72 \mathrm{~Gy}$ & $31 \mathrm{~Gy}$ \\
\hline Isodose & $50.5 \mathrm{~Gy}$ & $50 \mathrm{~Gy}$ \\
\hline Right optic nerve & $8.73 \mathrm{~Gy}$ & $8.45 \mathrm{~Gy}$ \\
\hline Left optic nerve & $7.60 \mathrm{~Gy}$ & $7.9 \mathrm{~Gy}$ \\
\hline Optic chiasma & $7.84 \mathrm{~Gy}$ & $7.75 \mathrm{~Gy}$ \\
\hline
\end{tabular}

\section{Results:-}

Of the 923 cases who received Gamma knife radiosurgery at this centre till Sep 2019, 152 cases with pituitary tumors underwent the procedure. 24 out of 152 cases received Gamma knife surgery as primary therapy. Out of these , 38 cases were of functional adenomas and 114 were non-funtional. Male is to female ratio was $1.3: 1$. The average tumor volume was $4.02 \mathrm{CC}$ and the average dose of radiation was 17.08 grey with the average tumor coverage being $94.59 \%$. The follow-up has ranged from 6 months to 10 years.

There has been 8 patients lost to follow up. 22 out of 24 patients which received gamma knife radiosurgery primarily not only exhibited tumour control (defined as unchanged or reduced tumour volume in follow up) but also showed subtle improvement in status viz recovery of vision. The clinical improvement, if any, in cases where gamma knife surgery was offered as adjunctive postoperative therapy for residual lesion, was ignored to offset any confounding factor generated by spontaneous recovery over a period of time from iatrogenic neurological paresis caused by surgery. Four cases of tumor progression were noted in the present series, three of those patients underwent surgery and one patient was unwilling for surgery. Two patient had deterioration vision, but they also showed tumor progression.

\section{Discussion:-}

In the treatment of pituitary adenomas, radiotherapy is classically indicated in cases of incomplete resection or recurrent tumors, functioning tumors uncontrolled by medical therapy and patients inoperable or who refuse surgery.

The objectives of radiotherapy are the control of tumor growth and/or the normalization of hormonal secretion, the maintenance of pituitary function and preservation of neurological function, especially visual acuity. Prasad reported a control rate of tumor growth $67-100 \%$ with conventional radiotherapy [15]. Brada et al. reported tumor progression-free survival at 10 and 20 years of $94 \%$ and $89 \%$, respectively [16]. Petrovich et al., also in a retrospective series of 78 patients treated only with the radiosurgery and a median prescribed dose of 15 Gy, reported a $96 \%$ tumor control, with volume reduction (> 50\%) in $29 \%$ of cases after 36 months median follow-up [17]. Izawa et al., after mean follow up of 24 months in 79 patients, reported local tumor control in $93.6 \%$ of patients, with reduction in $24.1 \%$. They prescribed a mean marginal dose of $22.5 \mathrm{~Gy}$. The lower rate of tumor shrinkage in our series is probably related to a lower dose prescribed [18].

\section{Conclusions:-}

RS is an effective and safe therapeutic option in the management of selected patients with pituitary adenomas. The short latency of the radiation response, the highly acceptable radiological and hormonal control and absence of complications at this early follow-up are consistent with literature.

\section{References:-}

1. Laws ER, Ebersold MJ, Piepgras DG: The results of transsphenoidal surgery in specific clinical entities, in Laws ER, Randall RV, Kern EB (eds): Management of Pituitary Adenomas and Related Lesions with Emphasis on Transsphenoidal Microsurgery. New York: Appleton-Century-Crofts, 1982, pp 277-305

2. Laws ER Jr, Vance ML: Radiosurgery for pituitary tumors and craniopharyngiomas. Neurosurg Clin N Am 10:327-336, 1999

3. Chandler WF, Schteingard DE, Lloyd RV, McKeever PE, Ibarra- Perez G: Surgical treatment of Cushing's disease. J Neurosurg 66:204-212, 1987

4. Friedman RB, Oldfield EH, Nieman LK, Chrousos GP, Doppman JL, Cutler GB Jr, et al: Repeat transsphenoidal surgery for Cushing's disease. J Neurosurg 71:520-527, 1989

5. Mampalam TJ, Tyrrell JB, Wilson CB: Transsphenoidal microsurgery for Cushing disease. A report of 216 cases. Ann Intern Med 109:487-493, 1988 
6. Backlund EO: The history and development of radiosurgery. In: Lunsford LD (ed) Stereotactic Radiosurgery UpdateProceedings of the International Stereotactic Radiosurgery Symposium, Pittsburg, PA1991. Elsevier Science NewYork 1991, pp 1-7

7. Emmanuel IG: Symposium pituitary tumours (3) historical aspects of radiotherapy, present treatment technique and results. Clin Radiol 17: 154-160, 1996

8. Luft R: The treatment of Cushing's syndrome. Acta Med Scand 124: 227-251, 1946

9. Snyder PJ, Fowble BF, Schatz NJ, Savino PJ, Genarelli TA: Hypopituitarism following radiation therapy of pituitary adenomas.

10. Littley MD, Shalet SM, Beardwell CG, Ahmed SR, Applegate G, Sutton ML: Hypopituitarism following external radiotherapy for pituitary tumours in adults. Quarterly $\mathbf{J}$

11. Med 262: 145-160, 1989

12. Jackson IMD, Nor'en G: Role of gamma knife surgery in the management of pituitary tumours. Endocrinol Metab Clin North America 28: 133-142, 1999

13. Grattan-Smith PJ, Morris JGL, Shores EA: Neuropsycologic abnormalities in patients with pituitary tumours. Acta Neurol Scand 86: 626-631, 1992

14. Brada M, Ford D, Ashley S: Risk of second brain tumour after conservative surgery and radiotherapy for pituitary adenomas. BMJ 304: 1343, 1992.

15. TsangRW, Laperriere NJ, Simpson WJ: Glioma arising after radiation therapy for pituitary adenomas. Cancer 72: 2227, 1993.

16. Prasad D: Clinical results of conformal radiotherapy and radiosurgery for pituitary adenoma. Neurosurg Clin $\mathrm{N}$ Am 2006, 17:129-141.

17. Brada M, Rajan B, Traish D, Ashley S, Holmes-Sellors PJ, Nussey S, Uttley D: The long-term efficacy of conservative surgery and radiotherapy in the control of pituitary adenomas. Clin Endocrinol (Oxf) 1993, 38:571-578.

18. Petrovich Z, Yu C, Giannotta SL, Zee CS, Apuzzo ML: Gamma Knife radiosurgery for pituitary adenoma: early results. Neurosurgery 2003, 53:51-59.

19. Izawa M, Hayashi M, Nakaya K, Satoh H, Ochiai T, Hori T, Takakura K: Gamma Knife radiosurgery for pituitary adenomas. J Neurosurg 2000, 93(Suppl 3):19-22. 